\title{
Viscosity of choline chloride-based deep eutectic solvents: Experiments and modeling
}

Nicolás F. Gajardo-Parra ${ }^{\dagger}$, Vincenzo P. Cotroneo-Figueroa ${ }^{\dagger}$, Paulo Aravena $^{\dagger}$, Velisa Vesovic ${ }^{\ddagger}$

and Roberto I. Canales ${ }^{\dagger}$ **

${ }^{\dagger}$ Departamento de Ingeniería Química y Bioprocesos, Pontificia Universidad Católica de Chile, Avenida Vicuña Mackenna 4860, Macul, Santiago, Chile

${ }^{\ddagger}$ Department of Earth Science and Engineering, Imperial College London, London, SW7 2AZ, United Kingdom.

*To whom correspondence should be addressed. E-mail: rocanalesm@ing.puc.cl 


\section{ABSTRACT}

Deep eutectic solvents (DES) have emerged as promising 'green' solvents, but their successful industrial application requires relatively low viscosity. DES prepared from choline chloride and glycols offer such possibility. Viscosity and density are reported for a number of DES obtained by mixing choline chloride and a glycol (ethylene glycol, 1,2-propanediol, 1,3-propanediol, and 1,4-butanediol). The measurements were performed at $101.3 \mathrm{kPa}$, at temperatures between $293.15 \mathrm{~K}$ and $333.15 \mathrm{~K}$, and for different mole ratios of the glycol and choline chloride. The viscosity was measured with a capillary viscometer, while the density was measured by means of a vibrating U-tube densimeter. The density and viscosity data have expanded relative uncertainties of $0.2 \%$ and $2.0 \%$, respectively, with a coverage factor of 2 . The viscosity of pure glycols was modeled using the extended hard-sphere (EHS) model that has its basis in kinetic theory and the molecular description of the fluid. Each DES was treated as a binary mixture, and the EHS model was used, with a mole average mixing rule, to calculate its viscosity. The measured DES viscosity data were represented with the average absolute deviation of $1.4 \%$ and a maximum deviation of $7 \%$.

Keywords

choline chloride, ethylene glycol, 1,2-propanediol, 1,3-propanediol, and 1,4-butanediol; Extended HardSphere Model; Liquid; Viscosity; DES 


\section{INTRODUCTION}

In the current literature, the term Deep Eutectic Solvents (DES) is used for mixtures composed of a hydrogen bond acceptor (HBA) and a hydrogen bond donor (HBD) that exhibit a very large melting point depression, resulting in the eutectic point of the mixture being much lower than the melting point of either of the pure constituents. The lowering of the melting point is due to the formation of strong hydrogen bonds between HBA and HBD and was originally reported by Abbott et al. ${ }^{1}$ for a mixture of choline chloride and urea. Recently, Martins et al. ${ }^{2}$ suggested that the DES concept should be used only for mixtures with a eutectic point that is lower than the one predicted by means of the ideal solid-liquid equilibrium. The existence of a large number of potential HBA and HBD compounds that can form DES of different compositions, and thus different thermophysical properties, has created an opportunity of producing new solvents. If the HBA and HBD happen to be naturally occurring compounds of low toxicity, environmentally friendly, and relatively cheap to produce, one can create 'green’ DES solvents that can replace many organic solvents in the current industrial use. The preparation of DES with tunable and tailor-made properties has been at the forefront of recent developments, and the literature abounds with both chemical characterization of new DES and proposed applications ${ }^{3}$.

DES have been recently reported for applications in the extraction of high-value solutes from plant matrices $^{4,5}$, in biomass processing ${ }^{6}$, as catalyst/solvent in reactions ${ }^{7}$, in liquid-liquid extraction for fractionation of complex mixtures ${ }^{8}$, among many others. The successful use of DES in varied applications is helped by the selection of different types of the binary, or in some cases ternary, combinations of HBAs with $\operatorname{HBDs}^{9}$, using compounds with low toxicity that are biodegradable ${ }^{10,11}$. However, there are also some issues that need to be addressed when selecting compounds for DES. For instance, not all the HBA-HBD combinations form a stable liquid phase at the full range of compositions ${ }^{2}$, many combinations could not be applicable in processes at temperatures above $373.15 \mathrm{~K}$ due to a noticeable mass loss ${ }^{12,13}$, and some HBDs produce a liquid phase with high viscosities at room temperature ${ }^{14,15}$. The high viscosity impedes flow and decreases the mass transfer rate of solutes, when, for instance, DES are used as extracting 
solvents; thus, making particular DES unsuitable for industrial applications. In some cases, the effect of high viscosity can be alleviated by the addition of a cosolvent or by a moderate increase in the process temperature. Another alternative is to prepare a DES with relatively low viscosity. One such DES can be created by combing different glycols (HBD) with choline chloride as the HBA ${ }^{8,13}$. The combination is very convenient for food, cosmetic, or pharmaceutical processes because choline chloride is a cheap, nontoxic, and biodegradable compound used as an additive in animal feed ${ }^{16}$. Furthermore, some glycols like 1,2-propanediol and 1,3-propanediol are generally recognized as safe (GRAS) food additives ${ }^{8}$. However, the use of ethylene glycol as the HBD compound is more questionable because of its reported toxicity ${ }^{17}$. Nevertheless, a mixture of choline chloride and ethylene glycol, at a mole ratio of 1:2, is one of the typical DES reported in literature for several 'green' applications and is considered as one of the reference systems for viscosity measurements ${ }^{13,18}$. In order to prepare a tailor-made DES of low viscosity, one needs not only to characterize them by measuring their viscosity and density but also to be able to predict the viscosity in order to fine-tune the DES composition for a particular application. Thus, the objective of this work is to underpin the development of low viscosity DES by (i) providing the experimental viscosity and density data that are reliable and with well-defined uncertainty; (ii) provide a model with a strong physical bases that will allow for accurate viscosity predictions.

The viscosity measurements of DES require careful preparation and the use of recommended viscometers that are fully characterized. In particular, water content needs to be monitored and kept to a minimum as DES are highly hygroscopic mixtures ${ }^{13}$. A number of workers ${ }^{13,18}$ have shown that a high water content markedly decreases the viscosity of DES. The current situation with the reported DES viscosity measurements that display large deviations between different research works is reminiscent of initial measurements on refrigerants in the late 1990s where unchecked water content also produced large differences in quoted viscosity values ${ }^{19}$. Furthermore, in order to develop reliable models, there is a need for viscosity data for varying HBA:HBD mole ratio. Currently, such data is available only for a limited number of DES ${ }^{20,21}$. 
Predicting the viscosity of liquids is hampered by the lack of the full underlying theory, resulting in a number of different approximate approaches ${ }^{22,23}$ based on simplified kinetic theory, corresponding states, free-volume concept, friction theory, density scaling, and relationship with residual entropy, among others. None of the general viscosity models available in the literature ${ }^{22,23}$ are particularly suitable for predicting the viscosity of DES, due to the high non-ideality of the mixture and the presence of hydrogen bonds. Hence, when it comes to predicting the DES viscosity, most of the workers have opted for fitting their measured data as either a polynomial in temperature or using an exponential dependence ${ }^{3,24,25}$. Although such a correlative approach is useful in representing a particular set of data, its predictive power is limited especially if the fitting is performed by treating DES as a pseudo-pure species. Further attempts in this direction were made using artificial neural networks to correlate larger sets of viscosity data belonging to a selection of different $\mathrm{DES}^{26,27}$. Only a few workers have opted to make use of existing predictive models by using DES experimental data to adjust the model parameters. In particular, FreeVolume Theory ${ }^{28,29}$ and Friction Theory ${ }^{30}$ were used with variable success. However, only one of these models ${ }^{28}$ treats the DES as a mixture for modeling purposes, thus allowing for greater flexibility in designing the optimum DES composition. The existing approaches to predict the viscosity based on molecular simulation ${ }^{31}$ still lack the necessary accuracy but potentially could enhance our understanding of the influence of molecular structures on viscosity.

For the viscosity of liquids and dense fluids in general, the only tractable solutions developed to date that take into account the molecular description of the fluid are based on the assumption that the molecules interact as hard spheres and that their collisions are uncorrelated. The resulting Enskog equation $^{32}$ for the viscosity of a dense hard-sphere fluid has formed the basis for several semi-theoretical approaches, two of which in particular have found practical application: the Assael and Dymond (AD) approach $^{33-35}$ and the Vesovic-Wakeham (VW) model ${ }^{36-38}$. The former was recently modified, extended, and successfully applied to predict the viscosity of diverse fluids and their mixtures with an uncertainty of $5-10 \%{ }^{23,39-41}$. The resulting extended hard-sphere (EHS) model ${ }^{39,40}$ retains the simplicity of earlier 
models, while maintaining the hard-sphere conceptual basis, and is ideally suited to analyze and predict the viscosity of DES.

In Section 1 of this work, we report and analyze the measured density and viscosity of DES consisting of choline chloride as the HBA and ethylene glycol, 1,2-propanediol, 1,3-propanediol, and 1,4butanediol as the HBDs, as well as the density and viscosity of pure ethylene glycol, 1,3-propanediol, and 1,4-butanediol. In section 2, we present the EHS model and test its ability to calculate the measured viscosity of pure glycols and DES. 
MATERIALS AND METHODS

\section{Chemicals}

Chemicals used for DES preparation are shown in Table 1 with their respective characteristics.

Choline chloride was used as the HBA, and ethylene glycol, 1,2-propanediol, 1,3-propanediol, and 1,4butanediol were used as the HBDs. All the DES were prepared in molar ratios of HBA:HBD from 1:2 to 1:6, when ethylene glycol was the HBD, and from 1:3 to 1:6 when 1,2-propanediol, 1,3-propanediol, and 1,4-butanediol were the HBDs.

Table 1: Chemical sample specification

\begin{tabular}{cccccc}
\hline Chemical name & $\boldsymbol{M} \mathbf{( g \cdot \mathbf { m o l } ^ { - \mathbf { 1 } } \mathbf { ) }}$ & CAS & Supplier & Type & Purity \\
\hline Choline chloride & 139.62 & $67-48-1$ & Acros Organics & - & $>0.990$ \\
Ethylene glycol & 62.07 & $107-21-1$ & Acros Organics & Anhydrous, & $>0.998$ \\
1,2-propanediol & 76.09 & $57-55-6$ & Acros Organics & Extra pure & $>0.990$ \\
1,3-propanediol & 76.09 & $504-63-2$ & Sigma-Aldrich & - & $>0.980$ \\
1,4-butanediol & 90.12 & $110-63-4$ & Acros Organics & - & $>0.990$ \\
\hline
\end{tabular}

\section{DES preparation}

In order to reduce the water content of DES to the minimum and thus pave the way for more accurate and reliable measurements, both HBA and HBD species were treated before preparing DES. Choline chloride, which is a very hygroscopic compound, was dried in a Schlenk line under a high vacuum $\left(10^{-4} \mathrm{mbar}\right)$ for three days, while ethylene glycol, 1,2-propanediol, 1,3-propanediol, and 1,4-butanediol were placed in molecular sieves for at least one day. The approach of drying HBA and HBD separately is preferred, as previous studies suggest that applying a low-pressure environment directly to the prepared DES, for reducing its water content, could affect its HBA:HBD composition ${ }^{13}$. Once the drying process has been completed, the DES were prepared gravimetrically using an analytical balance (Sartorius Practum 224-1s, Germany, uncertainty $\pm 0.1 \mathrm{mg}$ ) by adding the dried choline chloride (HBA) to HBD at the desired mole ratio into a flask under a nitrogen atmosphere. The flask was then tightly closed with a 
septum cap, and the mixture was placed in a sonicator and heated at about $353.15 \mathrm{~K}$ until a clear liquid was formed. The DES were kept in a desiccator to avoid any water intrusion, and the water content was measured using a Karl Fisher Coulometer (Metrohm 831KF, Switzerland). If the water content was above 0.1 wt. \%, the prepared DES were discarded, and a new sample was prepared. Table 2 summarizes the prepared DES, their composition, water content and molar mass.

Table 2: DES specifications

\begin{tabular}{ccccccc}
\hline \multirow{2}{*}{ Abbreviation } & HBA & HBD & XHBD & $\begin{array}{c}\text { HBA:HBD } \\
\text { mole ratio }\end{array}$ & $\begin{array}{c}\text { Water content } \\
\text { (wt.\%) }\end{array}$ & $\begin{array}{c}\boldsymbol{M} \\
\text { (g·mol } \mathbf{m}^{-1} \text { ) }\end{array}$ \\
\hline DES-A1 & choline chloride & ethylene glycol & 0.6675 & $1: 2.0071$ & 0.0790 & 87.85 \\
DES-A2 & choline chloride & ethylene glycol & 0.7499 & $1: 2.9987$ & 0.0651 & 81.46 \\
DES-A3 & choline chloride & ethylene glycol & 0.7999 & $1: 3.9974$ & 0.0389 & 77.58 \\
DES-A4 & choline chloride & ethylene glycol & 0.8332 & $1: 4.9965$ & 0.0579 & 74.99 \\
DES-A5 & choline chloride & ethylene glycol & 0.8571 & $1: 5.9982$ & 0.0465 & 73.14 \\
\hline DES-B1 & choline chloride & 1,2-propanediol & 0.7498 & $1: 2.9970$ & 0.0642 & 91.99 \\
DES-B2 & choline chloride & 1,2-propanediol & 0.8003 & $1: 4.0078$ & 0.0613 & 88.78 \\
DES-B3 & choline chloride & 1,2-propanediol & 0.8328 & $1: 4.9799$ & 0.0503 & 86.72 \\
DES-B4 & choline chloride & 1,2-propanediol & 0.8567 & $1: 5.9766$ & 0.0608 & 85.20 \\
\hline DES-C1 & choline chloride & 1,3-propanediol & 0.7509 & $1: 3.0141$ & 0.0355 & 91.92 \\
DES-C2 & choline chloride & 1,3-propanediol & 0.8001 & $1: 4.0013$ & 0.0340 & 88.79 \\
DES-C3 & choline chloride & 1,3-propanediol & 0.8328 & $1: 4.9799$ & 0.0581 & 86.71 \\
DES-C4 & choline chloride & 1,3-propanediol & 0.8567 & $1: 5.9766$ & 0.0446 & 85.20 \\
\hline DES-D1 & choline chloride & 1,4-butanediol & 0.7519 & $1: 3.0301$ & 0.0402 & 102.40 \\
DES-D2 & choline chloride & 1,4-butanediol & 0.8000 & $1: 3.9989$ & 0.0287 & 100.02 \\
DES-D3 & choline chloride & 1,4-butanediol & 0.8334 & $1: 5.0010$ & 0.0383 & 98.37 \\
DES-D4 & choline chloride & 1,4-butanediol & 0.8575 & $1: 6.0182$ & 0.0505 & 97.17 \\
\hline
\end{tabular}

Density and viscosity measurements

Density $(\rho)$ and dynamic viscosity $(\eta)$ were measured simultaneously for ethylene glycol, 1,3propanediol, 1,4-butanediol, and all the DES reported in Table 2 using an Anton Paar DMA4500M densitometer (Graz, Austria) coupled to an Anton Paar Lovis 2000ME microviscometer (Graz, Austria). The density measurements were performed in a vibrating tube, which was calibrated with double-distilled deionized and degassed water, provided by the manufacturer, and air at a temperature of $293.15 \mathrm{~K}$ and a 
pressure of $101.3 \mathrm{kPa}$. The temperature of the vibrating tube was measured with a Pt-100 thermometer. The uncertainty in the measured density and the temperature are $\pm 0.00005 \mathrm{~g} \cdot \mathrm{cm}^{-3}$ and $\pm 0.01 \mathrm{~K}$, respectively, as reported by Anton Paar. The dynamic viscosity measurements were performed in a capillary placed inside a temperature-controlled box. The capillary was filled with the sample, the temperature was set, and the angle of the box containing the capillary was automatically selected. The time taken for a density-calibrated steel ball to pass between two different points was measured by the apparatus and was used to determine the viscosity of the fluid. Three capillaries of an internal diameter of $1.59 \mathrm{~mm}, 1.80 \mathrm{~mm}$, and $2.50 \mathrm{~mm}$ were employed to perform the measurements for the range of viscosity of interest. The viscometer was calibrated with the standards provided by the manufacturer. Although the manufacturer quotes the uncertainty of $1.2 \%$ in the measured viscosity, our analysis based on our previous measurements on a number of standard fluids ${ }^{42,43}$ indicates that the uncertainty is nearer to $2 \%$. Hence, for the viscosity of pure glycols measured in this work, we associate a relative uncertainty of $2 \%$. For DES, the water content makes the viscosity much more difficult to measure accurately. Based on the analysis of published values of DES viscosity, where the water content is stated, it is at the moment unclear by how much water content present in the current measurements (0.029-0.079 wt\%) lowers the viscosity. Our own measurements ${ }^{13,44}$ indicate that no trend in viscosity is observable, within the estimated uncertainty, for the three measured DES (DES-A2, DES-C1, and DES-D1) in the range of water content (0.018-0.092 wt\%). Analysis of other data carried out in this work (see the Density and Viscosity measurements section) also support this conclusion. However, the two measurements reported by Gurkan et al. ${ }^{18}$ show a difference of $8.3 \%$ for the viscosity of DES-A1 at $313 \mathrm{~K}$ for 0.01 and 0.1 wt\% water content, respectively. So, although the viscosity of measured DES with a quoted water content, see Table 1 , still has the estimated uncertainty of $2 \%$, it is prudent to attribute a higher uncertainty to the viscosity of pure DES (without any water present). 


\section{THEORY}

In this work, we have made use of the extended hard-sphere (EHS) model ${ }^{39,40}$ to analyze, correlate, and predict the viscosity of the DES. The EHS model is the latest modification of the hard-sphere model of Assael, Dymond, and their collaborators ${ }^{22,33-35}$ that was originally developed to predict the viscosity of pure fluids and subsequently extended to mixtures. It is based on the postulate that the behavior of fluids is conformal and that the reduced viscosity $\left(\eta^{*}\right)$ is a universal function of the reduced molar volume $\left(V^{*}\right.$ $\left.=V_{\mathrm{m}} / V_{0}\right)$ that can be expressed in the following form,

$$
\log _{10}\left(1+\Delta \eta^{*}\right)=\sum_{i=1}^{7} a_{i} /\left(V^{*}\right)^{i}
$$

where the coefficients $a_{i}$ are available in literature ${ }^{39,40}$ and for completeness are presented in Table S1 in the Supporting Information. The reduced excess viscosity $\left(\Delta \eta^{*}\right)$ is defined by Ciotta et al. ${ }^{39}$,

$$
\Delta \eta^{*} \equiv \frac{16}{5}\left(2 N_{A}\right)^{1 / 3}\left(\frac{\pi}{M R T}\right)^{1 / 2} V_{m}^{2 / 3}\left(\frac{\eta-\eta^{(0)}}{R_{\eta}}\right)
$$

where $V_{\mathrm{m}}$ is the molar volume, $M$ is the molar mass, $N_{\mathrm{A}}$ is Avogadro's constant, $R$ is the gas constant, $R_{\eta}$ is the roughness factor, and $\eta^{(0)}$ is the zero-density viscosity.

In applications to real fluids, the roughness factor, $R_{\eta}$, is treated as an adjustable parameter, while the molar core volume, $V_{0}$, is treated as a weakly temperature-dependent adjustable function. Previous studies $^{22,35,39}$ on a number of pure fluids have demonstrated that it is possible to get a generic expression for $V_{0}$ as a function of temperature and molecular mass for a number of chemical families $(n$-alkanes, cycloalkanes, aromatics, alcohols, etc.). Analog molar-mass-based expressions exist for $R_{\eta}$ for a few chemical families. The resulting EHS model is capable of representing the viscosity of a large number of pure fluids within $\pm 5-10 \%$ and has been validated in the temperature range $110 \mathrm{~K}$ to $400 \mathrm{~K}$ and pressures up to $400 \mathrm{MPa}^{22,23,39}$. 


\section{RESULTS AND DISCUSSION}

\section{Density and viscosity measurements}

Density and dynamic viscosity measurements were carried out for ethylene glycol, 1,3-propanediol, 1,4butanediol, and the DES reported in Table 1 at temperatures between 293.15 and $333.15 \mathrm{~K}$ at $101.3 \mathrm{kPa}$. The density data obtained in this work are shown in Figure 1 and summarized in Table S2. For all the compounds reported, the density decreases, nearly linearly, with increasing the temperature. All the DES used in this work have a higher density than the pure HBD used in their preparation and at a fixed temperature, the density increases with a higher molar fraction of the HBA. Other workers ${ }^{45,46}$ have shown that the DES in general exhibit a non ideal behavior. For the systems studied in this work we cannot confirm this finding as the density of solid choline chloride has not been reported in literature and the first derivative of molar volume remains constant over the limited range of mole fractions studied. However, we would expect that the formation of strong hydrogen bonds between choline chloride and glycols, which generates a decrease in free volume, to play an important part in the observed change in density, as

demonstrated by other workers ${ }^{47,48}$. We also observe that at a fixed temperature, the density decreases with a higher molecular weight of the HBD, as a result of the observed decrease of the density of pure HBD. 

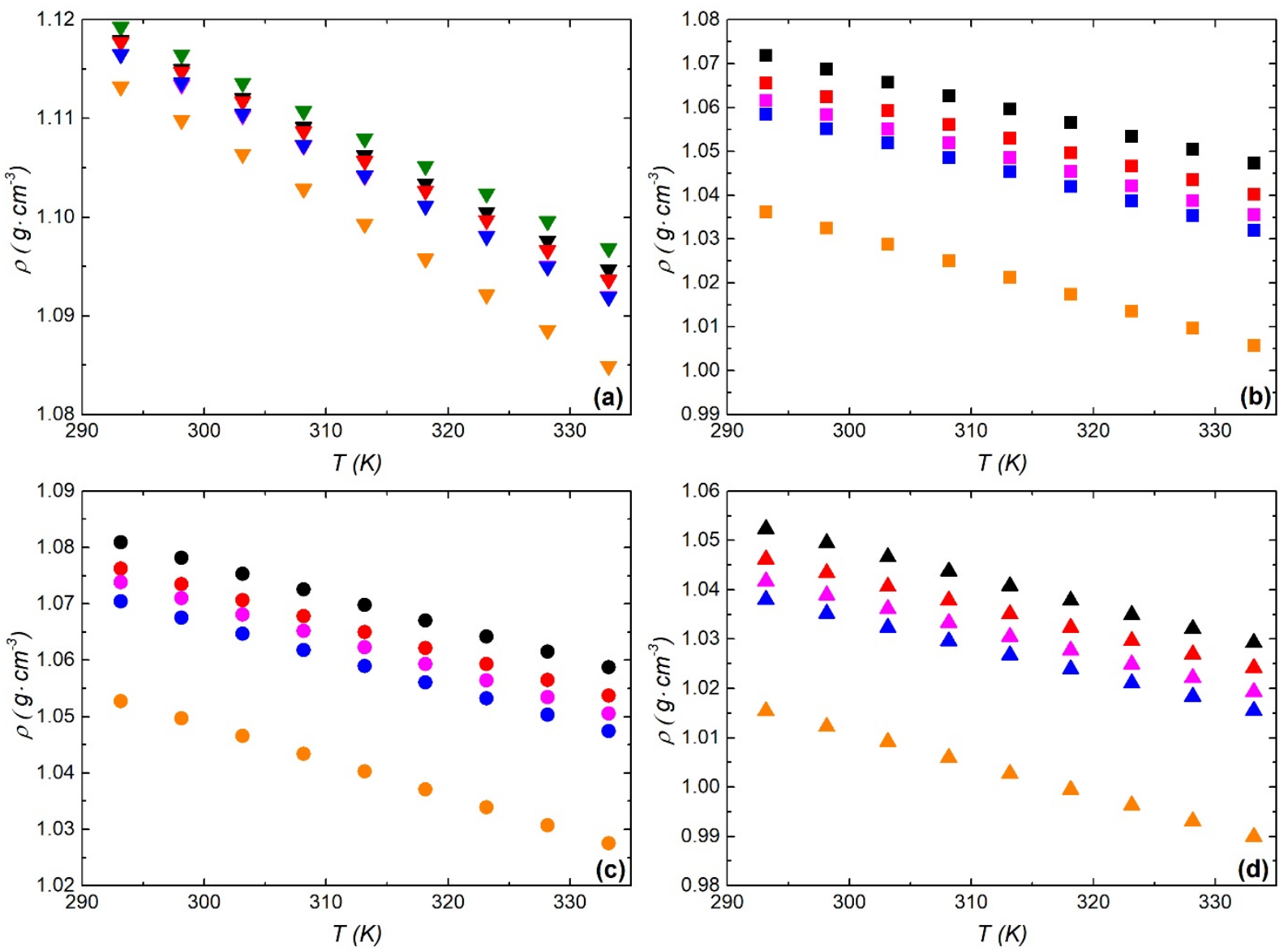

Figure 1. Density $\left(\mathrm{g} \cdot \mathrm{cm}^{-3}\right)$ as a function of the temperature (K) of (a) DES-A ( $\left.\nabla\right)$, (b) DES-B ( $\square$ ), (c) DES-C ( $(\circ)$ and (d) DES-D $(\triangle)$ at a pressure of $101.3 \mathrm{kPa}$. Symbols represent HBA:HBD molar ratios of

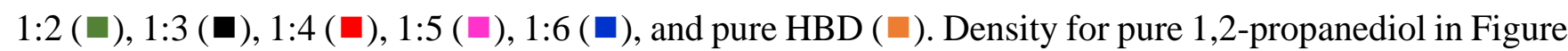
(b) was taken from Bajić et al. ${ }^{49}$

Viscosity data obtained in this work are shown in Figure 2 and summarized in Table S3. In general, the viscosity decreases markedly with an increase in temperature. At a fixed temperature, the viscosity increases when choline chloride (HBA) is added to the mixture. The increase can be mostly attributed to the formation of hydrogen bonds, as discussed above, that results in loss of molecular mobility. We also observe that viscosity is higher for DES that contain normal glycols (HBD) with a longer chain length, as a result of the observed increase in the viscosity of pure glycols. For DES (DES-B) containing isomeric glycol species (1,2-propanediol) viscosity is, except at the highest temperature, higher than the viscosity 
of DES (DES-C) containing normal glycol species (1,3-propanediol). This again can be traced back to the viscosity behavior of two pure glycol species, and it emphasizes the importance of intermolecular forces in determining viscosity. The viscosity of 1,2-propanediol is only higher than the viscosity of 1,3propanediol below $300 \mathrm{~K}$, although the density of the later is on average $1.7 \%$ higher than that of 1,2propanediol in the temperature range under consideration.
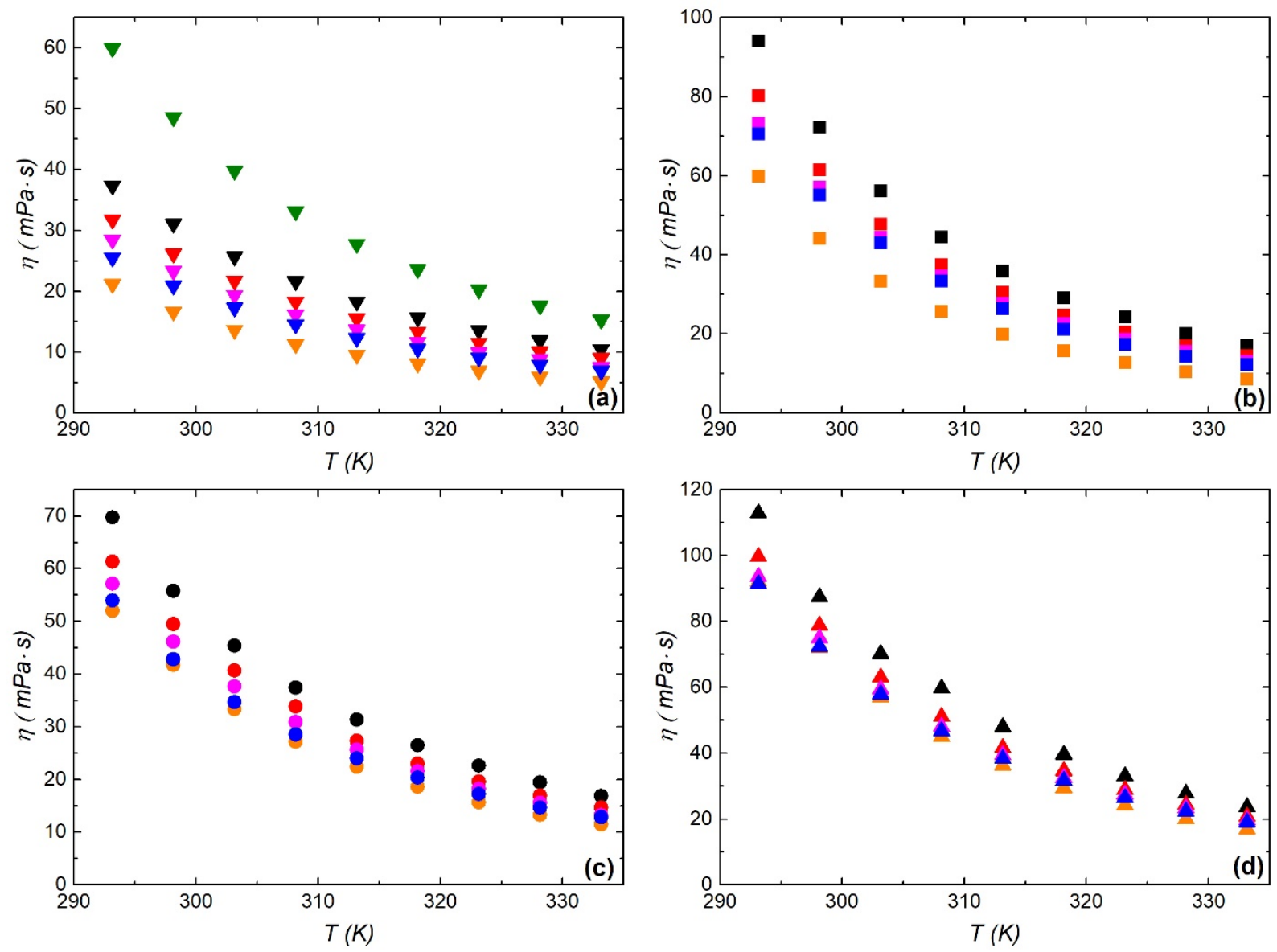

Figure 2. Viscosity (mPa·s) as a function of the temperature $(K)$ of (a) DES-A ( $\nabla)$, (b) DES-B ( $\square$ ), (c)

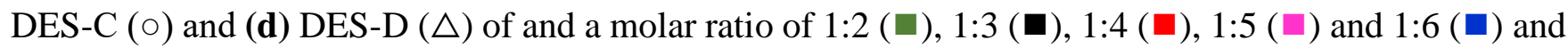
pure HBD $(\square)$ at a pressure of $101.3 \mathrm{kPa}$. Viscosity for pure 1,2-propanediol in Figure (b) was taken from Bajić et al. ${ }^{49}$

Density data obtained in this work were compared with literature for ethylene glycol, 1,3propanediol, and 1,4-butanediol, as shown in Figure 3(a), and with DES-A, DES-B, and DES-D in Figure 
3(b). For glycols, see Fig 3(a), we observe an excellent agreement. The density deviations between the measured and literature values do not exceed $0.05 \%$ for most sets. The only exception is some of the measurements for 1,4-butanediol. In particular, the agreement with Yang et al..$^{50}$ deteriorates at a higher temperature, but deviations never exceed $0.1 \%$, while the measurements of Moosavi et al. ${ }^{51}$ and Czechowski et al. ${ }^{52}$, that broadly agree with each other, are on average $0.1-0.15 \%$ above our density values. Nevertheless, in each case, the agreement is within the combined estimated uncertainty of both sets of measurements. For DES, the agreement between the measured and literature values is slightly worse, but on average, the deviations do not exceed $0.2 \%$, which is within the estimated uncertainty of our measurements and well inside the combined uncertainty. Not surprisingly, most measurements exist for a well-studied DES-A1 (choline chloride-ethylene glycol 1:2) mixture. The measurements from 7 research teams are consistent with our measurements to within $0.1 \%$. Only data of Mjalli et al..$^{53}$ exhibits larger deviations of up to $-0.22 \%$. For other systems, only measurements of DES-A3 (choline chlorideethylene glycol 1:4) mixture of Ozturk et al. ${ }^{20}$ show slightly higher deviations, when compared with our measured values, of up to $0.21 \%$, that increase with increasing temperature.
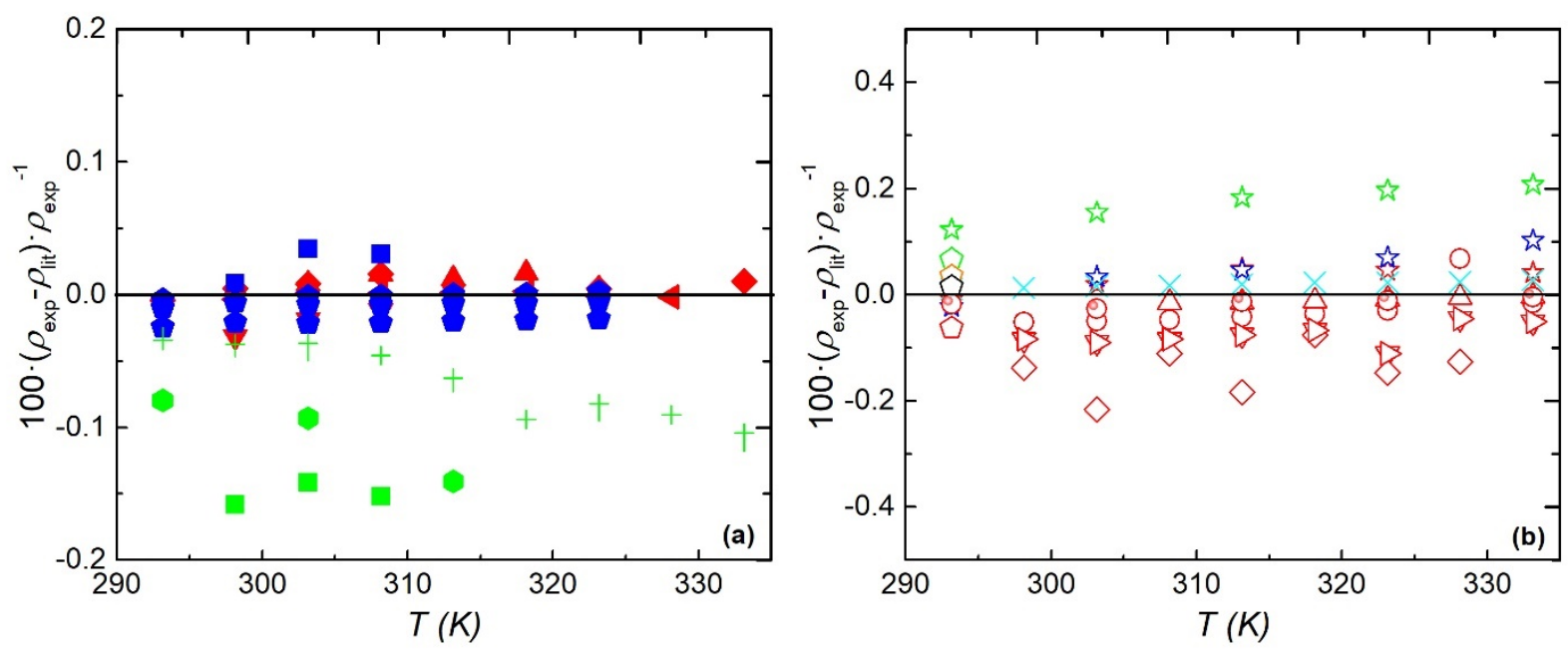

Figure 3. Percentage deviations $100 \cdot\left(\rho_{\text {exp. }}-\rho_{\text {lit. }}\right) / \rho_{\text {exp. }}$ of the experimental density data, $\rho_{\text {exp. }}$, measured in this work, from the literature values, $\rho_{\text {lit. }}$ of (a) glycols and (b) DES. Literature data was reported for: (i) ethylene glycol by Zhao et al. ${ }^{54}$ (solid, red, up triangle), Sun et al. ${ }^{55}$ (solid, red, down triangle), Carvalho et al. ${ }^{56}$ (solid, red diamond), and Quijada et al. ${ }^{57}$ (solid, red, left-pointing triangle); (ii) 1,3propanediol by Živković and co-workers ${ }^{49,58,59}$ (solid, blue pentagon), and Moosavi et al. ${ }^{51}$ (solid, blue 
square); (iii) 1,4-butanediol by Grineva and $Z_{\text {huravlev }}^{60}$ (green bar), Moosavi et al. ${ }^{51}$ (solid, green square), Czechowski et al. ${ }^{52}$ (solid, green hexagon), and Yang et al. ${ }^{50}$ (green plus); (iv) DES-A1 by Leron et al. ${ }^{61}$ (open, red circle), Harifi-Mood et al. ${ }^{62}$ (open, red, up triangle), Bagh et al. ${ }^{63}$ (open, red, down triangle), Mjalli et al. ${ }^{53}$ (open, red diamond), Shahbaz and coworkers ${ }^{64,65}$ (open, red, right-pointing triangle), Abbott et al. ${ }^{66}$ (open, red pentagon), Ozturk et al. ${ }^{20}$ (open, red star), and Gajardo-Parra et al. ${ }^{13}$ (red bubbled circle); (v) DES-A2 by Ozturk et al. ${ }^{20}$ (open, blue star), and Abbott et al. ${ }^{66}$ (open, blue pentagon); (vi) DES-A3 by Ozturk et al. ${ }^{20}$ (open, green star) and Abbott et al. ${ }^{66}$ (open, green pentagon); (vii) DES-B1 by Vuksanović et al. ${ }^{67}$ (cyan cross); (viii) DES-D1 by Abbott et al. ${ }^{66}$ (open, orange pentagon); (ix) DES-D2 by Abbott et al. ${ }^{66}$ (open, black pentagon).

Viscosity data obtained in this work were compared with literature for ethylene glycol, 1,3propanediol, and 1,4-butanediol, as shown in Figure 4(a), and with DES-A, DES-B, and DES-D in Figure 4(b). The agreement with glycol literature data, see Figure 4(a), is on average within 4\%, with only 4 data points showing larger deviations of up to $-5.6 \%$. A few sets of measurements $49,51,55,59,68$ display a weak, positive temperature trend with respect to our data. The reported uncertainty of literature values ranges from 1.0-2.5\%, and thus broadly speaking, the overall agreement is within the combined uncertainty of measurements. The comparison of our measured DES viscosity values with the reported literature values indicates large deviations, as high as 50\%, as illustrated in Figure 4(b). As discussed before, this is primarily due to the presence of small amounts of water in the DES samples. Not all the papers report the water content, but when they report low values, we observe a reasonable agreement with our measurements. In particular, our viscosity values are in agreement with Harifi-Mood ${ }^{62}$ (to within 6-8\%), Gurkan et al. ${ }^{18}$ ( -4\%), and our previous measurements ${ }^{13}$ (to within 2-4\%) for DES-A1 and with Vuksanović et al. ${ }^{67}$ (to within 5-6\%) for DES-B1. All of them report a water content below 0.1 wt\%, but no trend in viscosity values with respect to the water content could be established between different sets of measurements; most likely, the trend is masked by the uncertainty of the viscosity measurements. One would expect that as the temperature decreases and the viscosity increases, the same amount of water would have a greater impact on lowering the viscosity of the mixture. Interestingly, no systematic temperature trend in deviations has been observed between different sets of measurements, further indicating that the water content below $0.1 \mathrm{wt} \%$ does not influence viscosity within the quoted 
measurement uncertainty. The only set of measurements, with a reported water content $(<0.02 \mathrm{wt} \%)$,

where we observe larger deviations, is that of Mjalli and Ahmed ${ }^{69}$. Their values are 13-21\% lower than our values in the temperature range $293-333 \mathrm{~K}$.
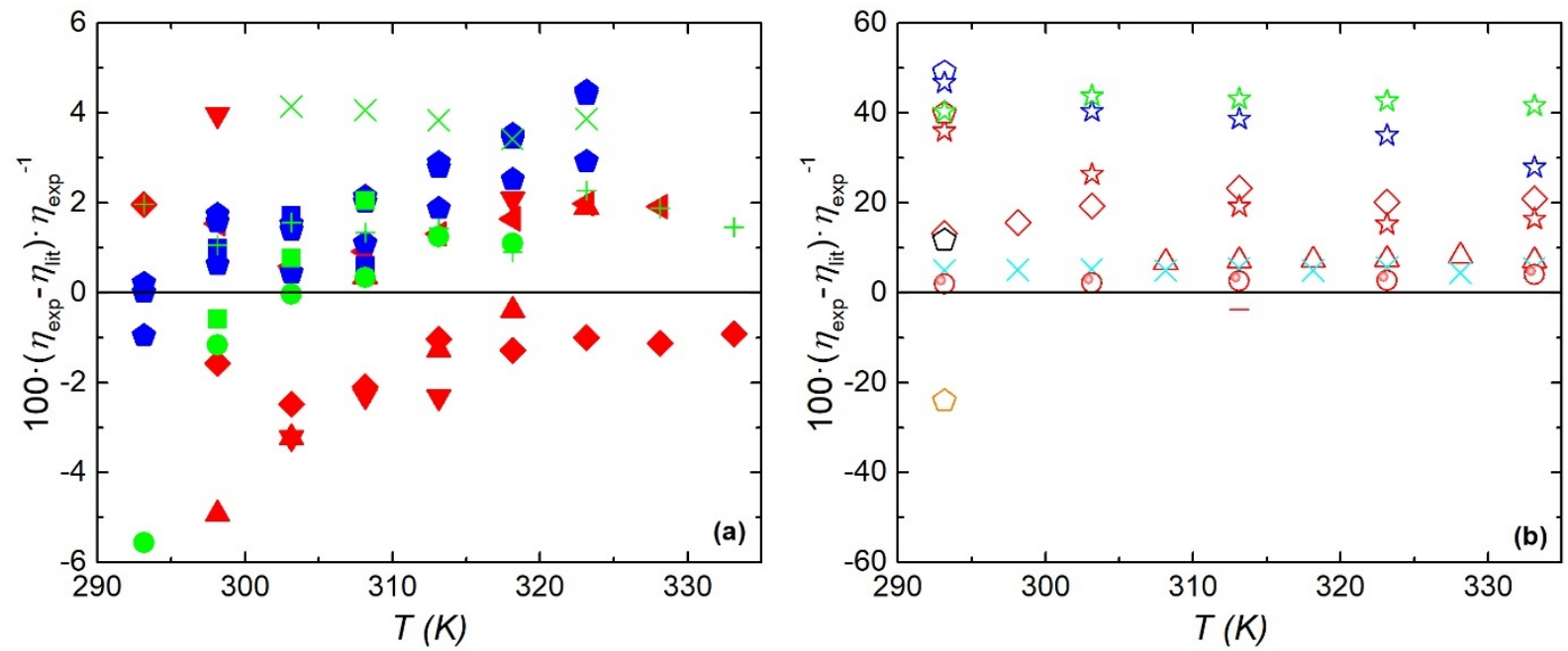

Figure 4. Percentage deviations $100 \cdot\left(\eta_{\text {exp. }}-\eta_{\text {lit. }}\right) / \eta_{\text {exp. }}$ of the experimental viscosity data, $\eta_{\text {exp. }}$, measured in this work from the literature values, $\eta_{\text {lit. }}$ of (a) glycols and (b) DES Literature data was reported for: (i) ethylene glycol by Zhao et al. ${ }^{54}$ (solid, red, up triangle), Sun et al. ${ }^{55}$ (solid, red, down triangle), Carvalho et al. ${ }^{56}$ (solid, red diamond), Quijada et al. ${ }^{57}$ (solid, red, right-pointing triangle); (ii) 1,3-propanediol by Živković and co-workers ${ }^{49,58,59}$ (solid, blue pentagon), Moosavi et al. ${ }^{51}$ (solid, blue square); (iii) 1,4-butanediol by Nain et al. ${ }^{68}$ (solid, green circle), Moosavi et al. ${ }^{51}$ (solid, green square), Saleh et al. ${ }^{70}$ (green cross) and Yang et al. ${ }^{50}$ (green plus); (iv) DES-A1 by Harifi-Mood et al. ${ }^{62}$ (open, red, up triangle), Mjalli and Abdel Jabbar ${ }^{71}$ (open, red diamond), Ozturk et al. ${ }^{20}$ (open, red star), Gajardo-Parra et al. ${ }^{13}$ (red, bubbled circle), Abbott et al. ${ }^{66}$ (open, red pentagon), Mjalli and Ahmed ${ }^{69}$ (open, red diamond), and Gurkan et al. ${ }^{18}$ (red dash); (v) DES-A2 by Ozturk et al. ${ }^{20}$ (open, blue star), and Abbott et al. ${ }^{66}$ (open, blue pentagon); (vi) DES-A3 by Ozturk et al. ${ }^{20}$ (open, green star); (vii) DES-B1 by Vuksanović et al. ${ }^{67}$ (cyan cross); (viii) DES-D1 by Abbott et al. ${ }^{66}$ (open, orange pentagon) and (ix) DES-D2 by Abbott et al. ${ }^{66}$ (open, black pentagon).

Viscosity modeling of pure glycols

We first examine the measured viscosity of pure glycols (ethylene glycol, 1,3-propanediol, and 1,4-butanediol) that represent the first three members of the homologous chemical series. The estimated 
molar core volumes, $V_{0}$, exhibited a linear dependency on molar mass $(M)$, and for each glycol, $V_{0}$ decreased linearly with increasing temperature. Hence, we choose a simple function,

$$
V_{o, g l y c o l}\left(m^{3} \cdot m o l^{-1}\right)=b_{1} M+\frac{b_{2}+b_{3} M}{T-b_{5}}+b_{4}
$$

to represent the molar core volumes, $V_{0}$, of ethylene glycol, 1,3-propanediol, and 1,4-butanediol. The measured viscosity of three pure glycols consisting of 27 data points have been fitted to Eqs (1-3), treating coefficients $b_{1}$ to $b_{4}$, together with $R_{\eta}$ for each glycol, as adjustable parameters. The values of the fitted coefficients are given in Tables 3 and 4. The optimal set of parameters was obtained by minimizing the sum of absolute deviations between the calculated and measured viscosity.

Table 3. Coefficients for the representation of molar core volume in Equation 3.

\begin{tabular}{cc}
\hline $\boldsymbol{i}$ & $\boldsymbol{b}_{\boldsymbol{i}}$ \\
& \\
\hline $\mathbf{1}$ & $8.96056 \times 10^{-4}$ \\
$\mathbf{2}$ & $3.41806 \times 10^{-4}$ \\
$\mathbf{3}$ & $5.20078 \times 10^{-2}$ \\
& \\
$\mathbf{4}$ & $-2.19643 \times 10^{-5}$ \\
\hline
\end{tabular}

Table 4. Coefficient $b_{5}$, Equation 3, and roughness factors for different glycols

\begin{tabular}{lcc}
\hline & $\boldsymbol{b}_{5} / \boldsymbol{K}$ & $\boldsymbol{R}_{\boldsymbol{\eta}}$ \\
\hline ethylene glycol & 0 & 1.116
\end{tabular}




\begin{tabular}{lcc}
\hline 1,2-propanediol & 28.177 & 1.057 \\
1,3-propanediol & 0 & 1.266 \\
1,4-butanediol & 0 & 1.370 \\
\hline
\end{tabular}

The parameter $b_{5}$ has been taken as zero for the members of the homologous series and non-zero for isomeric species; 1,2 propanediol in the present work. The zero-density viscosity which is required for the calculation of reduced viscosity, Eq. (2), has been estimated using Chung et al. method ${ }^{72,73}$. As this value corresponds to the viscosity of glycol in the dilute gas state, it is 3 to 4 orders of magnitude smaller than the measured viscosity. Hence, for the purposes of correlating the measured viscosity, we have taken a constant value of $\eta^{(0)}=7.0 \mu \mathrm{Pa} \cdot \mathrm{s}$ for each glycol of interest. The uncertainty introduced in the calculated viscosity is less than $0.1 \%$, which is an order of magnitude smaller than the estimated experimental uncertainty. The experimental uncertainty in the measured viscosity and limited temperature and density range of the available data precludes a unique determination of $V_{0}$ and $R_{\eta}$. This is perennial problem in determining model parameters using the measured thermophysical data and has been noted before $\mathrm{e}^{40,73-75}$. We have further constrained the roughness factor $R_{\eta}$ to increase with the molar mass of the glycol. Although a resulting trend is nearly linear, see Table 4, we have not attempted to fit the three $R_{\eta}$ parameters to produce a generic expression analogous to Eq. (3) as it would lead to a further deterioration in the calculated viscosity. Figure 5 illustrates the deviations of the correlated viscosity values from the measured ones in terms of (a) temperature and (b) molar mass, while Table 5 provides some statistical measures of the goodness of fit, namely Absolute Average Deviation (AAD), Maximum Deviation (MD) and Bias. 

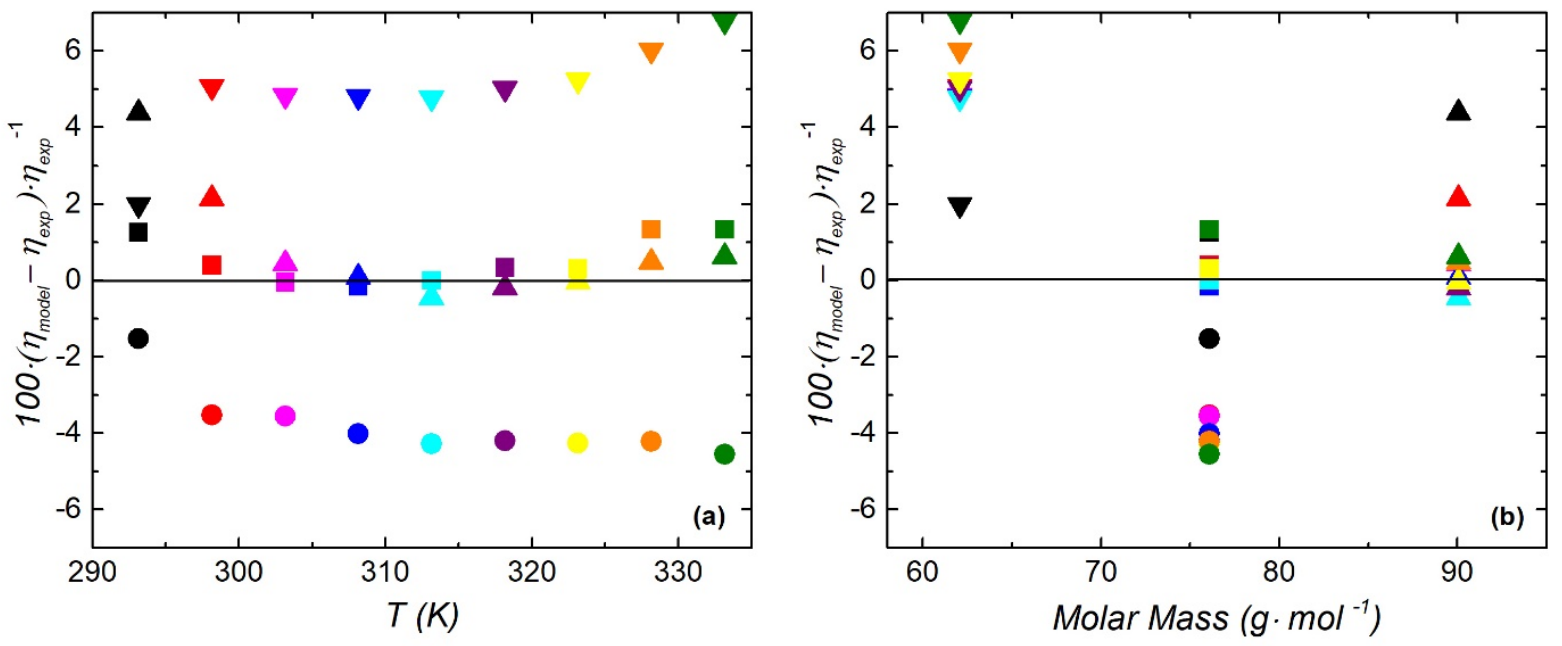

Figure 5. Deviations, $\left(100 \cdot\left(\eta_{\text {model }}-\eta_{\text {exp }}\right) / \eta_{\text {exp }}\right)$, in correlated the viscosity of pure glycols as a

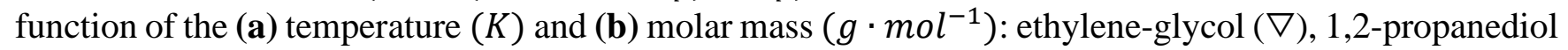

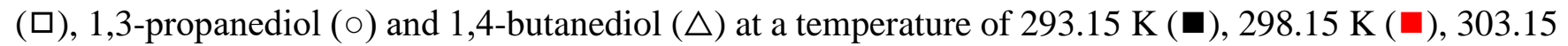

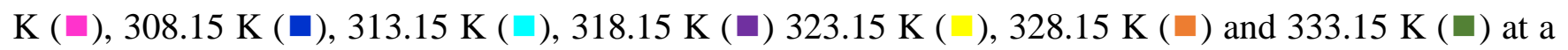
pressure of $101.3 \mathrm{kPa}$.

Table 5. Evaluation of the developed EHS model against experimental data

\begin{tabular}{cccc} 
& AAD $^{a}$ & MD $^{b}$ & Bias $^{c}$ \\
& $\%$ & $\%$ & $\%$ \\
\hline ethylene glycol & 5.0 & 6.8 & 5.0 \\
1,2-propanediol & 0.6 & 1.3 & 0.5 \\
1,3-propanediol & 3.8 & -4.6 & -3.8 \\
1,4-butanediol & 1.0 & & 0.8 \\
DES- $\boldsymbol{A}$ & 2.1 & 4.4 & 0.4 \\
DES-B & 1.2 & -7.0 & 0.0
\end{tabular}



DES-C

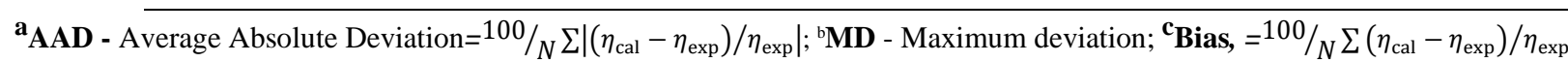

Overall, the agreement between the calculated and the measured viscosity is within the combined uncertainty of the experimental measurements and the EHS model. However, the deviations, displayed in Figure 5, for each glycol studied exhibit a weak temperature dependence and for ethylene glycol and 1,3propanediol a bias larger than the experimental uncertainty. Hence, it would be possible to improve the goodness of fit by further optimizing the roughness parameter, $R_{\eta}$. For instance, the reduction of the roughness parameter for ethylene glycol from 1.116 to 1.070 would result in deviations from experimental data being within experimental uncertainty with $\mathrm{AAD}=1.1 \%$, $\mathrm{Bias}=0.6 \%$, and $\mathrm{MD}=2.4 \%$. We have refrained from doing so, as it would be detrimental to the extension of the current EHS model to DES.

\section{Viscosity modeling of DES}

In order to apply the extended hard-sphere model to calculate the viscosity of mixtures, one either requires mixing rules ${ }^{22}$ or an estimate of the effective molecular mass $s^{23,41,76}$. In either approach, one needs to know the viscosity of both components in order to determine the relevant pure species $V_{0}$ and $R_{\eta}$. For the DES mixtures measured in this work, one of the components, the HBA (chlorine chloride), is in a solid-state at the temperatures of interest; thus precluding a direct determination of parameters from the viscosity. Instead, a mixing rule must be postulated to determine a pseudo $V_{0}$ and $R_{\eta}$ for choline chloride using measured DES data. As the DES mixtures are in general non-ideal, simple mixing rules will not be suitable for a full range of composition, as has been demonstrated for other non-ideal systems ${ }^{22}$. However, the DES composition is usually such that the mole fraction of HBA (or HBD) does not cover a large range 
away from the pure species. Hence, based on our previous studies ${ }^{23,39}$, we opted for the simple, mole average mixing rules for the molar core volume. ,

$$
V_{0, \text { mix }}=x_{\text {diol }} V_{0, \text { glycol }}+x_{c c} V_{0, c c}
$$

where $x_{\mathrm{i}}$ is the mole fraction of each species, $V_{0, \text { glycol }}$ is given by Eq. (3), and $V_{0, \text { cc }}$ is pseudo molar core volume of choline chloride. We analyzed the measured viscosity of DES belonging to family C (choline chloride $+1,3$ propanediol) and concluded that $V_{0 \text {,cc }}$ is conformal to $V_{0}$ of 1,3 -propanediol and can be expressed as,

$$
V_{0, \mathrm{cc}}=c+V_{01,3 \text { propanediol }}
$$

where $c$ is a constant determined by recourse to experimental data and given in Table 6. Analysis using

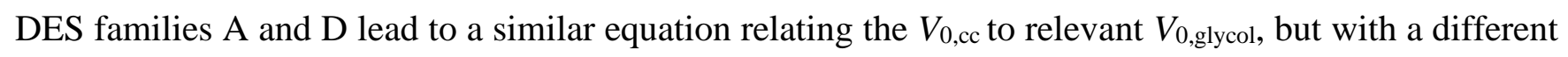
value of constant $c$. The observed conformal nature of the pseudo core volume of choline chloride that allows for a simple shift along the temperature axis is most likely a result of a limited range of mole fraction of choline chloride studied in this work $\left(x_{\mathrm{Cc}}=0-0.334\right)$ and to a certain extent a limited temperature range of current measurements. It is unlikely that the conformality of the core volumes, expressed by Eq (4), will extend over the whole compositional range, especially as the two components belong to very different chemical families. Our previous work ${ }^{23,41,76}$, on using the effective molecular weight to shift $V_{0}$ curves onto a common function, would indicate that, in general, a simple temperature shift will not induce conformality between different chemical families.

The mixture data for the DES families A, C, and D were fitted using the EHS model, including the mole average mixing rule for the molar core volume, by treating $R_{\eta}$ for each mixture as an adjustable parameter. The resulting roughness factors showed a uniform behavior as a function of mole fraction of choline chloride, and were fitted to,

$$
R_{\eta, \mathrm{DES}}=R_{\eta, \mathrm{glycol}}+d x_{\mathrm{cc}}+e x_{\mathrm{cc}}^{2}
$$




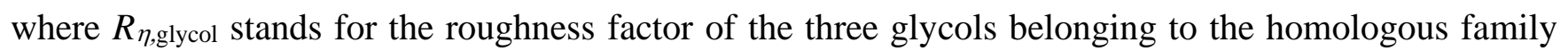
(ethylene glycol, 1,3-propanediol, and 1,4 butanediol) and coefficients $d$ and $e$ are given in Table 6. Again, the optimal set of parameters was obtained by minimizing the sum of absolute deviations between the calculated and measured viscosity. The resulting EHS model, Eqs. (1-6), is used to calculate the values of the viscosity of DES studied in this work. Figure 6 illustrates the deviations of the calculated viscosity from the measured ones, while Table 5 provides some statistical measures of the goodness of fit.

We observe an excellent agreement between the measured and calculated values with the overall AAD being smaller than the experimental uncertainty and only 3 data points showing deviations greater than 5\%. In general, no deviations show any systematic trend with temperature, with the exception of DES-A1 (choline chloride - ethylene glycol, 1:2 mole ratio) where a strong temperature trend is observed. We note that DES-A1 mixture is the only DES measured where chlorine chloride mole fraction is as high as 0.334 . The latter would indicate that we are reaching the limit of using a simple mixing rule for molar core volume. 

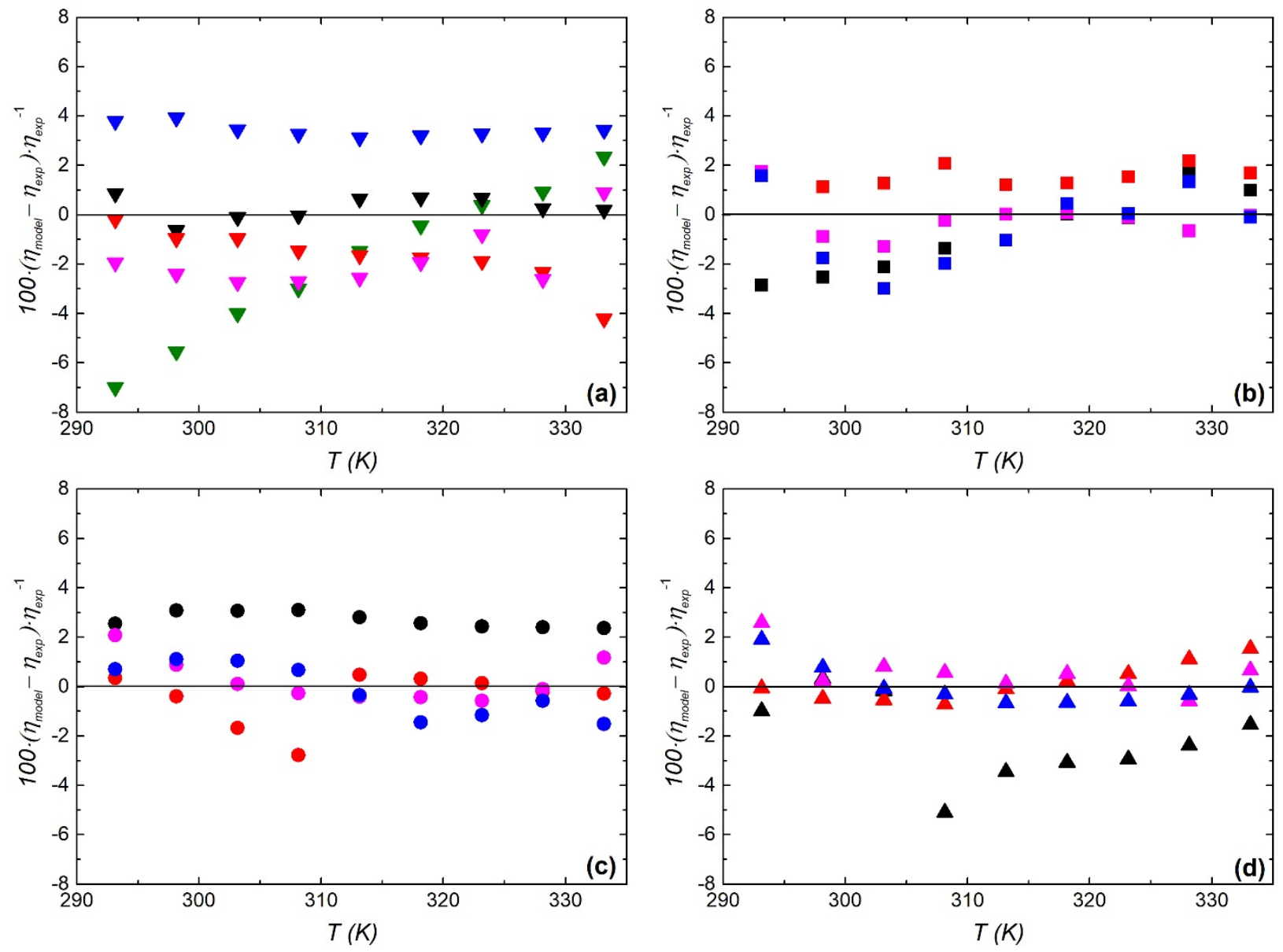

Figure 6. Deviations, $\left(100 \cdot\left(\eta_{\text {model }}-\eta_{\text {exp }}\right) / \eta_{\text {exp }}\right)$, in calculating the viscosity as a function of the temperature $(K)$ of (a) DES-A $(\nabla)$, (b) DES-B ( $\square)$, (c) DES-C (o), and (d) DES-D $(\triangle)$ at a molar ratio

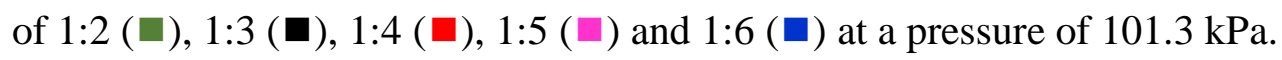

Table 6. Coefficients for the representations given by Equations 5-6

\section{1,2 propanediol}

\begin{tabular}{lcc}
\hline $\boldsymbol{c}$ & $4.50583 \times 10^{-5}$ & $4.50583 \times 10^{-5}$ \\
$\boldsymbol{d}$ & -0.5169 & -2.2614 \\
$\boldsymbol{e}$ & 6.6245 & 10.6892 \\
\hline
\end{tabular}

Other 3 glycols

.


DES-B consist of different ratios of chlorine chloride and 1,2-propanediol. The latter is an isomer of 1,3-propanediol and belongs to a different homologous series than the three glycols discussed so far. As such, we do not expect its molar core volume to be given by an Eq. (3) with parameter $b_{5}$ equal to zero. However, in order to analyze DES-B mixture data, we need to first establish the $V_{0}$ (and $R_{\eta}$ ) for $1,2-$ propanediol. As the measurements on 1,2-propanediol have not been performed as part of this work, we made use of the literature measurements of Bajić et al. ${ }^{49}$ Their data for 1,3-propanediol agrees with ours within the combined experimental uncertainty, and no systematic trends in deviations have been observed, see Figure 4. The initial analysis of the experimental viscosity data Bajić et al. ${ }^{49}$ indicated that the $V_{0}$ of 1,2-propanediol is conformal with the other glycols studied and that it can be calculated using the developed generic formula for molar core volume, Eq. (3) by making parameter $b_{5}$ non-zero. This corresponds to a temperature shift of the $\mathrm{V}_{0}$ curve of 1,2-propanediol to the generic one. Subsequently, the EHS model was fitted to the Bajić et al. experimental data ${ }^{49}$ using $b_{5}$ and $R_{\eta}$ as adjustable parameters. The optimal values of the two parameters for 1,2-propanediol are given in Table 4. Figure 5 illustrates the deviations of the correlated viscosity values from the measured ones, while Table 5 provides some statistical measures of the goodness of fit. The smaller AAD and MD obtained for this glycol is a direct result of using a substance-specific $V_{0}$ correlation, rather than a general one, Eq. (3), as was done for the other three glycols.

Once $V_{0}$ and $R_{\eta}$ for 1,2-propanediol have been established, the EHS model was fitted to DES-B mixture data, measured in this work, treating $R_{\eta}$ for each of the four DES-B mixtures as an adjustable parameter. The resulting roughness factors exhibited a quadratic relationship with the mole fraction of choline chloride present and were fitted to Eq. (6), where the coefficients $d$ and $e$ are given in Table 6. Figure 6 illustrates the deviations of the calculated viscosity values from the measured ones, while Table 5 provides some statistical measures of the goodness of fit. Again, we observe an excellent agreement between the measured and calculated values with the overall AAD being smaller than the experimental uncertainty and no data points showing deviations greater than $3 \%$. It is interesting to note that the 
variation of water content (0.0287 to 0.0790 wt\%) between different DES samples had no adverse effect on the ability of the present model to correlate and calculate the viscosity. This gives further credence to the hypothesis that the water content at this level does not influence the DES viscosity within its estimated uncertainty. 


\section{CONCLUSIONS}

Density and viscosity for 17 deep eutectic solvents based on choline chloride + glycol (ethylene glycol, 1,2-propanediol, 1,3-propanediol, and 1,4-butanediol) were measured in the range of temperatures from 293.15 to $333.15 \mathrm{~K}$, at mole ratios of HBA:HBD from 1:2 to 1:6, and at a pressure of $101.3 \mathrm{kPa}$. The density and viscosity decrease as the temperature increases, and with the addition of HBD (glycol). Replacing HBD in DES with the one with a longer carbon chain leads, at a constant temperature, to decrease in density and increase in viscosity.

The extended hard-sphere model was used to correlate the measured viscosity of the pure glycols. The resulting model can correlate the viscosity of four glycols with AAD of $2.6 \%$ and a maximum deviation of $6.8 \%$. It is possible to find more optimal parameters that would substantially decrease the deviations, but that would be detrimental to the ability of the model to calculate the viscosity of DES, and hence we refrained from doing so. The analysis of measured viscosity of DES indicates that, at least in the mole fraction range studied, the pseudo molar core volume of choline chloride is conformal to glycol one, which allows DES to be treated as a binary mixture for the modeling purposes. The parameters obtained for glycols and choline chloride were used in the EHS model, together with a simple mole average mixing rule for the molar core volume to calculate the viscosity of DES. The viscosities of the 17 DES studied in this work were calculated with the AAD of $1.4 \%$ and a maximum deviation of $7 \%$. The developed model can be used to predict the viscosity of other DES made from the same combinations of HBA and HBD species. 


\section{SUPPORTING INFORMATION}

Supporting Information is available for this manuscript. Table S1 - Coefficients of the universal correlation; Table S2 - Measured density of DES; Table S3 - Measured viscosity of DES.

\section{ACKNOWLEDGEMENT}

We acknowledge the funding from ANID Chile through the projects Fondecyt de Iniciación Nº 11160882 and PCI REDI170207. We would also thank the support of VRI-UC for funding the visit of Velisa Vesovic

to Pontificia Universidad Católica de Chile through their grant "Visitas de Investigación de Profesores Extranjeros 2019”.

\section{AUTHOR INFORMATION}

\section{Corresponding Author}

*E-mail: rocanalesm@ing.puc.cl. Telephone: +56 223547436.

\section{AUTHOR CONTRIBUTIONS}

The manuscript was written through contributions of all authors. All authors have given approval to the final version of the manuscript. 


\section{REFERENCES}

(1) Abbott, A. P.; Capper, G.; Davies, D. L.; Rasheed, R. K.; Tambyrajah, V. Novel Solvent Properties of Choline Chloride/Urea Mixtures. Chem. Commun. 2003, No. 1, 70-71.

(2) Martins, M. A. R.; Pinho, S. P.; Coutinho, J. A. P. Insights into the Nature of Eutectic and Deep Eutectic Mixtures. J. Solution Chem. 2019, 48 (7), 962-982.

(3) Alkhatib, I. I. I.; Bahamon, D.; Llovell, F.; Abu-Zahra, M. R. M.; Vega, L. F. Perspectives and Guidelines on Thermodynamic Modelling of Deep Eutectic Solvents. J. Mol. Liq. 2020, 298, 112183.

(4) Ruesgas-Ramón, M.; Figueroa-Espinoza, M. C.; Durand, E. Application of Deep Eutectic Solvents (DES) for Phenolic Compounds Extraction: Overview, Challenges, and Opportunities. J. Agric. Food Chem. 2017, 65 (18), 3591-3601.

(5) Zurob, E.; Cabezas, R.; Villarroel, E.; Rosas, N.; Merlet, G.; Quijada-Maldonado, E.; Romero, J.; Plaza, A. Design of Natural Deep Eutectic Solvents for the Ultrasound-Assisted Extraction of Hydroxytyrosol from Olive Leaves Supported by COSMO-RS. Sep. Purif. Technol. 2020, 248, 117054.

(6) da Costa Lopes, A. M.; Gomes, J. R. B.; Coutinho, J. A. P.; Silvestre, A. J. D. Novel Insights into Biomass Delignification with Acidic Deep Eutectic Solvents: A Mechanistic Study of $\beta$-O-4 Ether Bond Cleavage and the Role of the Halide Counterion in the Catalytic Performance. Green Chem. 2020, 22 (8), 2474-2487.

(7) Morais, E. S.; Freire, M. G.; Freire, C. S. R.; Coutinho, J. A. P.; Silvestre, A. J. D. Enhanced Conversion of Xylan into Furfural Using Acidic Deep Eutectic Solvents with Dual Solvent and Catalyst Behavior. ChemSusChem 2020, 13 (4), 784-790.

(8) Ozturk, B.; Gonzalez-Miquel, M. Alkanediol-Based Deep Eutectic Solvents for Isolation of 
Terpenoids from Citrus Essential Oil: Experimental Evaluation and COSMO-RS Studies. Sep. Purif. Technol. 2019, 227, 115707.

(9) Marcus, Y. Properties of Deep Eutectic Solvents BT - Deep Eutectic Solvents; Marcus, Y., Ed.; Springer International Publishing: Cham, 2019; pp 45-110.

(10) Paiva, A.; Craveiro, R.; Aroso, I.; Martins, M.; Reis, R. L.; Duarte, A. R. C. Natural Deep Eutectic Solvents - Solvents for the 21st Century. ACS Sustain. Chem. Eng. 2014, 2 (5), 1063-1071.

(11) Liu, Y.; Friesen, J. B.; McAlpine, J. B.; Lankin, D. C.; Chen, S.-N.; Pauli, G. F. Natural Deep Eutectic Solvents: Properties, Applications, and Perspectives. J. Nat. Prod. 2018, 81 (3), 679-690.

(12) Delgado-Mellado, N.; Larriba, M.; Navarro, P.; Rigual, V.; Ayuso, M.; García, J.; Rodríguez, F. Thermal Stability of Choline Chloride Deep Eutectic Solvents by TGA/FTIR-ATR Analysis. $J$. Mol. Liq. 2018, 260, 37-43.

(13) Gajardo-Parra, N. F.; Lubben, M. J.; Winnert, J. M.; Leiva, Á.; Brennecke, J. F.; Canales, R. I. Physicochemical Properties of Choline Chloride-Based Deep Eutectic Solvents and Excess Properties of Their Pseudo-Binary Mixtures with 1-Butanol. J. Chem. Thermodyn. 2019, 133, 272284.

(14) Hayyan, A.; Mjalli, F. S.; AlNashef, I. M.; Al-Wahaibi, Y. M.; Al-Wahaibi, T.; Hashim, M. A. Glucose-Based Deep Eutectic Solvents: Physical Properties. J. Mol. Liq. 2013, 178, 137-141.

(15) Aroso, I. M.; Paiva, A.; Reis, R. L.; Duarte, A. R. C. Natural Deep Eutectic Solvents from Choline Chloride and Betaine - Physicochemical Properties. J. Mol. Liq. 2017, 241, 654-661.

(16) Radošević, K.; Cvjetko Bubalo, M.; Gaurina Srček, V.; Grgas, D.; Landeka Dragičević, T.; Radojčić Redovniković, I. Evaluation of Toxicity and Biodegradability of Choline Chloride Based Deep Eutectic Solvents. Ecotoxicol. Environ. Saf. 2015, 112, 46-53. 
(17) Waring, W. S. Alcohols and Glycols Poisoning. Medicine (Baltimore). 2020, 48 (3), 185-188.

(18) Gurkan, B.; Squire, H.; Pentzer, E. Metal-Free Deep Eutectic Solvents: Preparation, Physical Properties, and Significance. J. Phys. Chem. Lett. 2019, 10 (24), 7956-7964.

(19) Assael, M. J.; Leipertz, A.; MacPherson, E.; Nagasaka, Y.; Nieto de Castro, C. A.; Perkins, R. A.; Ström, K.; Vogel, E.; Wakeham, W. A. Transport Property Measurements on the IUPAC Sample of 1,1,1,2-Tetrafluoroethane (R134a). Int. J. Thermophys. 2000, 21 (1), 1-22.

(20) Ozturk, B.; Parkinson, C.; Gonzalez-Miquel, M. Extraction of Polyphenolic Antioxidants from Orange Peel Waste Using Deep Eutectic Solvents. Sep. Purif. Technol. 2018, 206, 1-13.

(21) Guo, W.; Hou, Y.; Ren, S.; Tian, S.; Wu, W. Formation of Deep Eutectic Solvents by Phenols and Choline Chloride and Their Physical Properties. J. Chem. Eng. Data 2013, 58 (4), 866-872.

(22) Assael, M. J.; Goodwin, A. R. H.; Vesovic, V.; Wakeham, W. A. Experimental Thermodynamics Volume IX. Advances in Transport Properties; The Royal Society of Chemistry, 2014.

(23) Nguyen, T.-B.; Vesovic, V. Predicting the Viscosity of Liquid Mixtures Consisting of N-Alkane, Alkylbenzene and Cycloalkane Species Based on Molecular Description. Fluid Phase Equilib. 2019, 487, 58-70.

(24) Francisco, M.; van den Bruinhorst, A.; Kroon, M. C. Low-Transition-Temperature Mixtures (LTTMs): A New Generation of Designer Solvents. Angew. Chemie Int. Ed. 2013, 52 (11), 30743085.

(25) Lapeña, D.; Lomba, L.; Artal, M.; Lafuente, C.; Giner, B. Thermophysical Characterization of the Deep Eutectic Solvent Choline Chloride:Ethylene Glycol and One of Its Mixtures with Water. Fluid Phase Equilib. 2019, 492, 1-9.

(26) Adeyemi, I.; Abu-Zahra, M. R. M.; AlNashef, I. M. Physicochemical Properties of Alkanolamine- 
Choline Chloride Deep Eutectic Solvents: Measurements, Group Contribution and Artificial Intelligence Prediction Techniques. J. Mol. Liq. 2018, 256, 581-590.

(27) Benguerba, Y.; Alnashef, I. M.; Erto, A.; Balsamo, M.; Ernst, B. A Quantitative Prediction of the Viscosity of Amine Based DESs Using Sø-Profile Molecular Descriptors. J. Mol. Struct. 2019, 1184, 357-363.

(28) Crespo, E. A.; Costa, J. M. L.; Palma, A. M.; Soares, B.; Martín, M. C.; Segovia, J. J.; Carvalho, P. J.; Coutinho, J. A. P. Thermodynamic Characterization of Deep Eutectic Solvents at High Pressures. Fluid Phase Equilib. 2019, 500, 112249.

(29) Haghbakhsh, R.; Parvaneh, K.; Raeissi, S.; Shariati, A. A General Viscosity Model for Deep Eutectic Solvents: The Free Volume Theory Coupled with Association Equations of State. Fluid Phase Equilib. 2018, 470, 193-202.

(30) Haghbakhsh, R.; Raeissi, S.; Parvaneh, K.; Shariati, A. The Friction Theory for Modeling the Viscosities of Deep Eutectic Solvents Using the CPA and PC-SAFT Equations of State. J. Mol. Liq. 2018, 249, 554-561.

(31) van den Bruinhorst, A.; Spyriouni, T.; Hill, J.-R.; Kroon, M. C. Experimental and Molecular Modeling Evaluation of the Physicochemical Properties of Proline-Based Deep Eutectic Solvents. J. Phys. Chem. B 2018, 122 (1), 369-379.

(32) Chapman, S.; Cowling, T. The Mathematical Theory of Non-Uniform Gases., Cambridge.; Cambridge, 1991.

(33) Assael, M. J.; Dymond, J. H.; Papadaki, M.; Patterson, P. M. Correlation and Prediction of Dense Fluid Transport Coefficients. III. n-Alkane Mixtures. Int. J. Thermophys. 1992, 13 (4), 659-669.

(34) Gaciño, F. M.; Comuñas, M. J. P.; Fernández, J.; Mylona, S. K.; Assael, M. J. Correlation and Prediction of Dense Fluid Transport Coefficients. IX. Ionic Liquids. Int. J. Thermophys. 2014, 35 
(5), 812-829.

(35) Assael, M. J.; Dymond, J. H.; Papadaki, M.; Patterson, P. M. Correlation and Prediction of Dense Fluid Transport Coefficients. I. n-Alkanes. Int. J. Thermophys. 1992, 13 (2), 269-281.

(36) Vesovic, V.; Wakeham, W. A. Prediction of the Viscosity of Fluid Mixtures over Wide Ranges of Temperature and Pressure. Chem. Eng. Sci. 1989, 44 (10), 2181-2189.

(37) Royal, D. D.; Vesovic, V.; Trusler, J. P. M.; Wakeham, W. A. Prediction of the Viscosity of Dense Fluid Mixtures. Mol. Phys. 2003, 101 (3), 339-352.

(38) De Wijn, A. S.; Riesco, N.; Jackson, G.; Martin Trusler, J. P.; Vesovic, V. Viscosity of Liquid Mixtures: The Vesovic-Wakeham Method for Chain Molecules. J. Chem. Phys. 2012, 136 (7), 074514.

(39) Ciotta, F.; Trusler, J. P. M.; Vesovic, V. Extended Hard-Sphere Model for the Viscosity of Dense Fluids. Fluid Phase Equilib. 2014, 363, 239-247.

(40) Riesco, N.; Vesovic, V. Extended Hard-Sphere Model for Predicting the Viscosity of Long-Chain n-Alkanes. Fluid Phase Equilib. 2016, 425, 385-392.

(41) Nguyen, T. B.; Riesco, N.; Vesovic, V. Predicting the Viscosity of N-Alkane Liquid Mixtures Based on Molecular Description. Fuel 2017, 208, 363-376.

(42) Gajardo-Parra, N. F.; Campos-Franzani, M. I.; Hernández, A.; Escalona, N.; Canales, R. I. Density and Viscosity of Binary Mixtures Composed of Anisole with Dodecane, Hexadecane, Decalin, or 1,4-Dioxane: Experiments and Modeling. J. Chem. Eng. Data 2020, 65 (4), 2032-2043.

(43) Campos-Franzani, M. I.; Gajardo-Parra, N. F.; Pazo-Carballo, C.; Aravena, P.; Santiago, R.; Palomar, J.; Escalona, N.; Canales, R. I. Extraction of Guaiacol from Hydrocarbons as an Alternative for the Upgraded Bio-Oil Purification: Experimental and Computational 
Thermodynamic Study. Fuel 2020, 280, 118405.

(44) Cotroneo-Figueroa, V. P.; Gajardo-Parra, N. F.; López-Porfiri, P.; Leiva, Á.; González-Miquel, M.; Canales, R. I. Hydrogen Bond Donor and Alcohol Chain Length Effect on the Physicochemical Properties of Choline Chloride Based Deep Eutectic Solvents Mixed with Alcohols. J. Mol. Liq. Submitted.

(45) López-Porfiri, P.; Brennecke, J. F.; Gonzalez-Miquel, M. Excess Molar Enthalpies of Deep Eutectic Solvents (DESs) Composed of Quaternary Ammonium Salts and Glycerol or Ethylene Glycol. J. Chem. Eng. Data 2016, 61 (12), 4245-4251.

(46) Alizadeh, V.; Malberg, F.; Pádua, A. A. H.; Kirchner, B. Are There Magic Compositions in Deep Eutectic Solvents? Effects of Composition and Water Content in Choline Chloride/Ethylene Glycol from Ab Initio Molecular Dynamics. J. Phys. Chem. B 2020, 124 (34), 7433-7443.

(47) García, G.; Aparicio, S.; Ullah, R.; Atilhan, M. Deep Eutectic Solvents: Physicochemical Properties and Gas Separation Applications. Energy \& Fuels 2015, 29 (4), 2616-2644.

(48) Zhang, Q.; De Oliveira Vigier, K.; Royer, S.; Jerome, F. Deep Eutectic Solvents: Syntheses, Properties and Applications. Chem. Soc. Rev. 2012, 41 (21), 7108-7146.

(49) Bajić, D. M.; Ivaniš, G. R.; Visak, Z. P.; Živković, E. M.; Šerbanović, S. P.; Kijevčanin, M. L. Densities, Viscosities, and Refractive Indices of the Binary Systems (PEG200 + 1,2-Propanediol, +1,3-Propanediol) and (PEG400 + 1,2-Propanediol, +1,3-Propanediol) at (288.15 to 333.15) K and Atmospheric Pressure: Measurements and Modeling. J. Chem. Thermodyn. 2013, 57, 510-529.

(50) Yang, C.; Ma, P.; Zhou, Q. Excess Molar Volume, Viscosity, and Heat Capacity for the Mixtures of 1,4-Butanediol + Water at Different Temperatures. J. Chem. Eng. Data 2004, 49 (3), 582-587.

(51) Moosavi, M.; Motahari, A.; Omrani, A.; Rostami, A. A. Investigation on Some Thermophysical Properties of Poly(Ethylene Glycol) Binary Mixtures at Different Temperatures. J. Chem. 
Thermodyn. 2013, 58, 340-350.

(52) Czechowski, G.; Zywucki, B.; Jadzyn, J. Excess Molar Volumes of Binary Mixtures of Diols and Water. J. Chem. Eng. Data 1988, 33 (1), 55-57.

(53) Mjalli, F. S.; Vakili-Nezhaad, G.; Shahbaz, K.; Alnashef, I. M. Application of the Eötvos and Guggenheim Empirical Rules for Predicting the Density and Surface Tension of Ionic Liquids Analogues. Thermochim. Acta 2014, 575, 40-44.

(54) Zhao, T.; Zhang, J.; Guo, B.; Zhang, F.; Sha, F.; Xie, X.; Wei, X. Density, Viscosity and Spectroscopic Studies of the Binary System of Ethylene Glycol+dimethyl Sulfoxide at T=(298.15 to 323.15) K. J. Mol. Liq. 2015, 207, 315-322.

(55) Sun, S.; Niu, Y.; Gao, F.; Shen, J.; Wei, X. Solubility Properties and Spectral Characterization of Dilute SO2 in Binary Mixtures of Urea + Ethylene Glycol. J. Chem. Eng. Data 2015, 60 (1), 161170.

(56) Carvalho, P. J.; Fonseca, C. H. G.; Moita, M.-L. C. J.; Santos, Â. F. S.; Coutinho, J. A. P. Thermophysical Properties of Glycols and Glymes. J. Chem. Eng. Data 2015, 60 (12), 3721-3737.

(57) Quijada-Maldonado, E.; Meindersma, G. W.; de Haan, A. B. Viscosity and Density Data for the Ternary System Water(1)-Ethanol(2)-Ethylene Glycol(3) between 298.15K and 328.15K. J. Chem. Thermodyn. 2013, 57, 500-505.

(58) Živković, E. M.; Bajić, D. M.; Radović, I. R.; Šerbanović, S. P.; Kijevčanin, M. L. Volumetric and Viscometric Behavior of the Binary Systems Ethyl Lactate+1,2-Propanediol, +1,3-Propanediol, +tetrahydrofuran and +tetraethylene Glycol Dimethyl Ether. New UNIFAC-VISCO and ASOGVISCO Parameters Determination. Fluid Phase Equilib. 2014, 373, 1-19.

(59) Kijevčanin, M. L.; Živković, E. M.; Djordjević, B. D.; Radović, I. R.; Jovanović, J.; Šerbanović, S. P. Experimental Determination and Modeling of Excess Molar Volumes, Viscosities and 
Refractive Indices of the Binary Systems (Pyridine+1-Propanol, +1,2-Propanediol, +1,3Propanediol, and +glycerol). New UNIFAC-VISCO Parameters Determination. J. Chem. Thermodyn. 2013, 56, 49-56.

(60) Grineva, O. V; Zhuravlev, V. I. Densities and Dielectric Permittivities of Three Butanediols and Their Solutions with $10 \mathrm{Mol} \%$ Water. J. Chem. Eng. Data 1996, 41 (3), 604-607.

(61) Leron, R. B.; Soriano, A. N.; Li, M.-H. Densities and Refractive Indices of the Deep Eutectic Solvents (Choline Chloride + Ethylene Glycol or Glycerol) and Their Aqueous Mixtures at the Temperature Ranging from 298.15 to 333.15 K. J. Taiwan Inst. Chem. Eng. 2012, 43 (4), 551-557.

(62) Harifi-Mood, A. R.; Buchner, R. Density, Viscosity, and Conductivity of Choline Chloride + Ethylene Glycol as a Deep Eutectic Solvent and Its Binary Mixtures with Dimethyl Sulfoxide. J. Mol. Liq. 2017, 225, 689-695.

(63) Bagh, F. S. G.; Shahbaz, K.; Mjalli, F. S.; AlNashef, I. M.; Hashim, M. A. Electrical Conductivity of Ammonium and Phosphonium Based Deep Eutectic Solvents: Measurements and Artificial Intelligence-Based Prediction. Fluid Phase Equilib. 2013, 356, 30-37.

(64) Shahbaz, K.; Mjalli, F. S.; Hashim, M. A.; AlNashef, I. M. Prediction of Deep Eutectic Solvents Densities at Different Temperatures. Thermochim. Acta 2011, 515 (1-2), 67-72.

(65) Shahbaz, K.; Baroutian, S.; Mjalli, F. S.; Hashim, M. A.; AlNashef, I. M. Densities of Ammonium and Phosphonium Based Deep Eutectic Solvents: Prediction Using Artificial Intelligence and Group Contribution Techniques. Thermochim. Acta 2012, 527, 59-66.

(66) Abbott, A. P.; Harris, R. C.; Ryder, K. S. Application of Hole Theory to Define Ionic Liquids by Their Transport Properties. J. Phys. Chem. B 2007, 111 (18), 4910-4913.

(67) Vuksanović, J.; Kijevčanin, M. L.; Radović, I. R. Effect of Water Addition on Extraction Ability of Eutectic Solvent Choline Chloride+ 1,2-Propanediol for Separation of Hexane/Heptane+ethanol 
Systems. Korean J. Chem. Eng. 2018, 35 (7), 1477-1487.

(68) Nain, A. K. Molecular Interactions in Binary Mixtures of Formamide with 1-Butanol, 2-Butanol, 1,3-Butanediol and 1,4-Butanediol at Different Temperatures: An Ultrasonic and Viscometric Study. Fluid Phase Equilib. 2008, 265 (1), 46-56.

(69) Mjalli, F. S.; Ahmed, O. U. Physical Properties and Intermolecular Interaction of Eutectic Solvents Binary Mixtures: Reline and Ethaline. Asia-Pacific J. Chem. Eng. 2016, 11 (4), 549-557.

(70) Saleh, M. A.; Begum, S.; Begum, S. K.; Begum, B. A. Viscosity of Dilute Aqueous Solutions of Some Diols. Phys. Chem. Liq. 1999, 37 (6), 785-801.

(71) Mjalli, F. S.; Abdel Jabbar, N. M. Acoustic Investigation of Choline Chloride Based Ionic Liquids Analogs. Fluid Phase Equilib. 2014, 381, 71-76.

(72) Chung, T. H.; Lee, L. L.; Starting, K. E. Applications of Kinetic Gas Theories and Multiparameter Correlation for Prediction of Dilute Gas Viscosity and Thermal Conductivity. Ind. Eng. Chem. Fundam. 1984, 23 (1), 8-13.

(73) Poling, B. E.; Prausnitz, J. M.; O’Connell, J. P. The Properties Of Gases And Liquids Fifth Edition McGraw-Hill. 2001.

(74) Castro-Palacio, J. C.; Hellmann, R.; Vesovic, V. Dilute Gas Viscosity of $n$-Alkanes Represented by Rigid Lennard-Jones Chains. Mol. Phys. 2016, 114 (21), 3171-3182.

(75) Clark, G. N. I.; Haslam, A. J.; Galindo, A.; Jackson, G. Developing Optimal Wertheim-like Models of Water for Use in Statistical Associating Fluid Theory (SAFT) and Related Approaches. Mol. Phys. 2006, 104 (22-24), 3561-3581.

(76) Malta, J. Á. M. S. C.; Calabrese, C.; Nguyen, T. B.; Trusler, J. P. M.; Vesovic, V. Measurements and Modelling of the Viscosity of Six Synthetic Crude Oil Mixtures. Fluid Phase Equilib. 2020, 
505, 112343. 
For Table of Contents Only

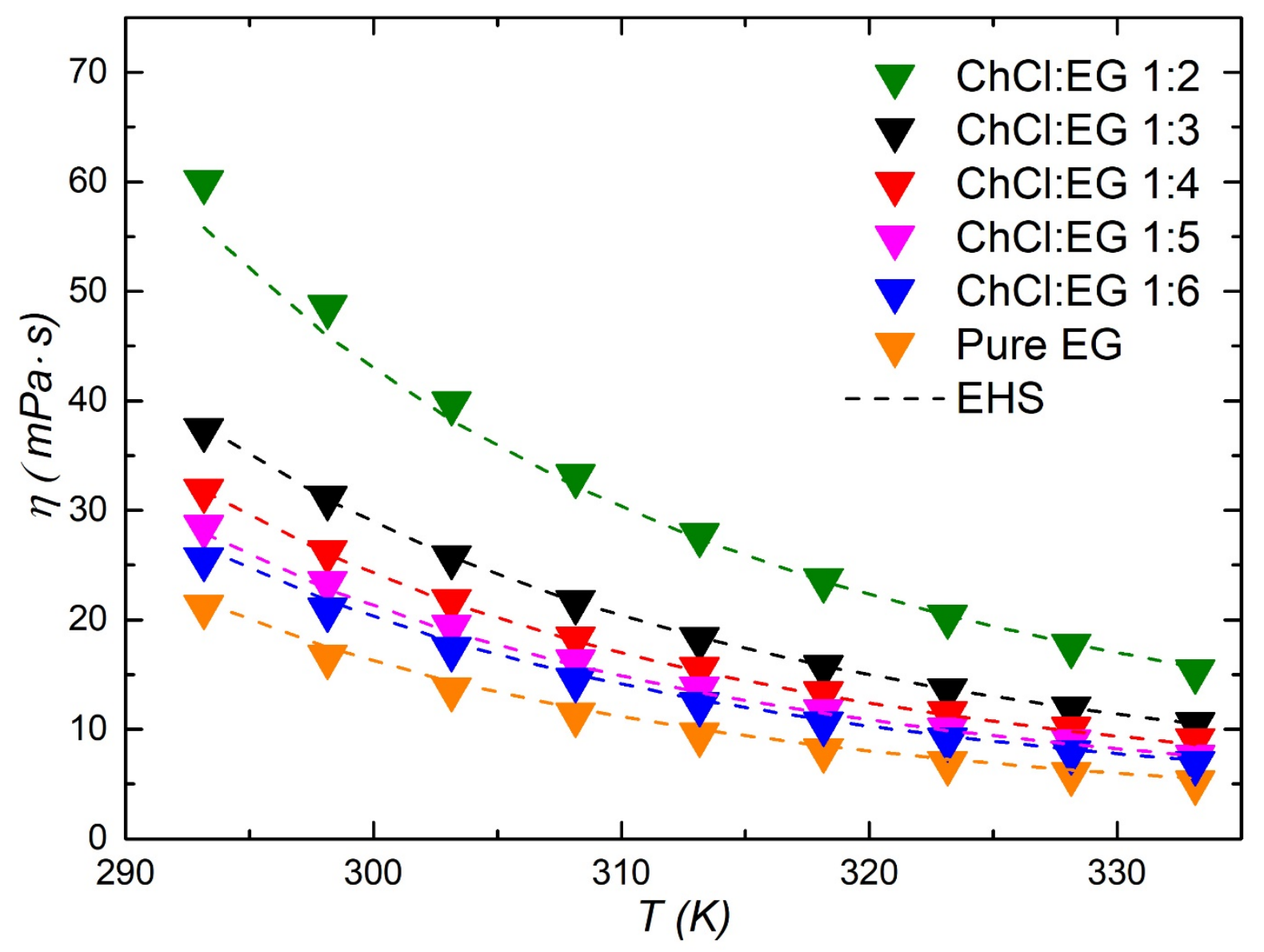

